\title{
Language variation in source texts and their translations
}

\author{
The case of L3 in film translation ${ }^{1,2}$
}

\author{
Montse Corrius and Patrick Zabalbeascoa \\ Universitat de Vic / Universitat Pompeu Fabra
}

In addition to the two languages essentially involved in translation, that of the source text (L1) and that of the target text (L2), we propose a third language (L3) to refer to any other language(s) found either or both texts. L3 may appear in the source text (ST) or the target text (TT), actually appearing more frequently in STs in our case studies. We present a range of combinations for the convergence and divergence of L1, L2 and L3, for the case of feature films and their translations using examples from dubbed and subtitled versions of films, but we are hopeful that our tentative conclusions may be relevant to other modalities of translation, audiovisual and otherwise. When L3 appears in an audiovisual ST, we find a variety of solutions whereby L3 is deleted from or adapted to the TT. In the latter case, L3 might be rendered in a number of ways, depending on factors such as the audience's familiarity with L3, and the possibility that L3 in the ST is an invented language.

Keywords: multilingualism, audiovisual, translation, invented, pseudo-language, secondary language, variation, equivalence, third language, transfer

\section{Introduction}

The aim of this article is to present a proposal for analysing the translation of multilingual texts, and in particular, the concept of third language (L3) as a feature of translations (TT) and their source texts (ST), which may become a problem for translators. ${ }^{3}$ We present a wide range of possible solution-types (Zabalbeascoa, 2000b, 2004), many of which are illustrated by examples from feature films, and their translated versions.

Our starting point is the observation that there seems to be a growing preference in recent years for producing texts (written, oral, or audiovisual) that are not 
entirely monolingual (see Meylaerts 2006), thus imbuing them with a more multicultural appearance, probably due, in part, to a will to reflect the spectacular progress that has taken place in communication, information, technology, transport and globalisation in general. In this respect, it should be noted that although multilingualism has always been present in Hollywood productions (Bleichenbacher 2008), the number of films requiring the audience to deal with communication in more than one language has increased since the 1980's and 1990's (Heiss 2004). Many popular English-language films display some other language(s) to a greater or lesser degree, and these constitute instances of the kind of language variation we wish to refer to as L3. French Kiss (Lawrence Kasdan 1997), for instance, as the title of the film suggests, adds instances of French; Monsoon Wedding (Mira Nair 2001) colours the English with Hindi and Punjabi; Land and Freedom (Ken Loach 2004) adds some Spanish, since the film is set in the Spanish Civil War. In science fiction, Blade Runner (Ridley Scott 1982) includes an invented language, Cityspeak, that contains a mixture of words and expressions from natural languages (Spanish, French, Chinese, Hungarian and Japanese). In these examples, French, Spanish, Hindi, Punjabi and Cityspeak are secondary languages in an audiovisual (AV) source text, such as a film or TV product to be translated, whose main language (L1) is English. We propose that secondary languages such as these be called the third language or L3. As Bassnett (1992:2) puts it, "what is generally understood as translation involves the rendering of a source language ... into the target language". Like Bassnett, when most people talk about translating they tend to think in terms of only two languages: the ST language (L1), and the TT language (L2). However, as pointed out by Meylaerts (2006), this approach neglects the fact that not all discourses are totally monolingual. The third language (L3) is neither L1 in the ST nor L2 in the TT; it is any other language(s) found in either text (Corrius 2008). L3 poses specific problems for translation, and should not be dismissed without much thought about the variables involved. L3 is used here as a short form for the third language; $\mathrm{L} 3^{\mathrm{ST}}$ is short for the $\mathrm{L} 3$ of a source text, and $\mathrm{L} 3^{\mathrm{TT}}$ for the third language of the target text (translation). L3 does not include or overlap with the notion of the third code, as proposed by Frawley (1984:168), or Baker (1993:245), or any concepts such as translationese (Newmark 1988), or dubbese (Antonini 2008), which cover TT language that is 'tainted' with ST language influences and usually viewed pejoratively. The terms, "translation", "ST", and "TT" are used here to refer exclusively to texts intended for different audiences or readerships, as we will not be dealing with intratextual translation (e.g. when a character in a film acts as interlingual interpreter for others), which is one of the possible scenarios of L3.

Although multilingualism is commonly used in contemporary Hollywood films (see Bleichenbacher 2008) it is something that is obviously not new or ex- 
clusive to audiovisual texts; rather, multilingual texts have existed over the centuries, in different languages and different formats. Examples abound, and it is not our intention to provide more than a few. Delabastita (2002) provides a most insightful study of the display of languages, language combinations and language variation (L3, for us), both interlingual and intralingual, in Shakespeare's Henry $V$, and the solutions provided by its various translators; Charlotte Brontë includes French utterances in her novel Jane Eyre; and Umberto Eco (2000) created and used a pseudo-medieval North Italian language in his novel Baudolino, which, as he acknowledges, (Eco 2003:34-35) created many problems for translators of the novel. Yet, despite the use of multilingualism by many authors, and bearing in mind the complex, varied relationships between multilingualism and translation, traditional translation theory tends to assume that translation involves only monolingual texts, one language for the ST, and one for its corresponding translation: "translation proper" (Jakobson, 1959) as it has traditionally been perceived. This paper intends to extend the translation theoretical discussion by studying the nature of third languages (L3) as they appear or are portrayed, in films mostly, and how they might affect, and be dealt with, in translation; that is to say, how L3 is and could be rendered in translation.

\section{The nature of $\mathrm{L} 3$, the third language}

The third language is a feature of multilingual texts and communication acts. Each language ( $\mathrm{L} 1, \mathrm{~L} 2$, and any number of different $\mathrm{L}^{\mathrm{ST}}$ and $\left.\mathrm{L} 3^{\mathrm{TT}}\right)$ may be a distinct, independent language or an instance of relevant language variation, sufficient to signal more than one identifiable speech community being portrayed or represented within a text. Thus, $\mathrm{L} 3^{\mathrm{ST}}$ may be a language variety (e.g. a dialect) of L1, (likewise for $\mathrm{L}^{\mathrm{TT}}$ with regard to L2). L3, then, may be either the representation or portrayal of a natural, living language, dialect or variety, or a fictitious, invented, language (e.g. Cityspeak). For a natural L3, there may be a genuine attempt to provide a realistic representation of an existing language, but L3 may also be a fake or pseudolanguage that merely displays one or two stereotypical traits - e.g. pseudo-Italian in A Fish called Wanda (Charles Crichton 1988), or pseudo-medieval language.

We can also accommodate in our L3 proposal the case, studied by Delabastita (2010), of representations of L3 by means of different varieties or styles of L1, whereby the ST is actually monolingual, but includes specific traits that make-believe the presence of other languages (i.e. language supposedly spoken as opposed to language really spoken). Probably, the most outstanding instance of this can be found in the BBC sit-com 'Allo 'Allo (Delabastita 2010:196). Delabastita identifies three different languages (French, German and English) which are supposedly 
Table 1. L3 types and subtypes for ST (and conversely valid for TT).

\begin{tabular}{ll}
\hline Types of L3 in ST & $\begin{array}{l}\text { L3 }^{\text {ST }} \text { subtypes (as a matter of degree, on a cline) } \\
\text { maximum }\end{array}$ \\
\hline $\begin{array}{l}\text { natural languages (even L2 } \\
\text { or special forms of L1) }\end{array}$ & How familiar: from max. to min. (exotic or unknown) \\
& How real(istic): from max. to min. (fake or pseudo-language) \\
& How standard: from max. to min. (non-standard variety) \\
invented & $\begin{array}{l}\text { How strongly L1-based: from max. to min. (weak or no L1 basis, } \\
\text { i.e. entirely invented or based on another natural language) }\end{array}$ \\
\hline
\end{tabular}

spoken in this television series, also compounded by various foreign accents in which they are supposedly spoken, depending on each character's national background and whether or not they are 'supposed' to be speaking their own language. The remarkable feat in the script is that all of this is achieved without really resorting to any other language than English. For each 'supposed' language, as Delabastita calls it, English is spoken with a different accent or style, resulting in seven different varieties of 'supposed' languages and accents, and five varieties of English actually spoken to portray them. For this to work in the way Delabastita proposes we must assume or accept that certain foreign words and expressions like dummkopf or mon chérie are to be considered as English (borrowings). For the purpose of this paper, what we say here for L3 can hold true even if L3 is 'supposed' as in the case of 'Allo 'Allo.

Our point of departure is that the ST is potentially made up of a main language $\mathrm{L} 1$ plus a third language, $\mathrm{L}^{\mathrm{ST}}$, namely, [ST languages $\left.=\mathrm{L} 1+\mathrm{L} 3^{\mathrm{ST}}\right]$. For Grutman (1998) the minimum requirement for a text to be identified as a multilingual text (a text that uses two or more languages) is the presence of at least a single foreign word, although, in light of the above, this depends on the translator's criterion for what constitutes genuine foreignness, as opposed to borrowings, for example. A translator may decide that sombrero is a Spanish word in an English text, or an English word borrowed from Spanish. Likewise, though more debatable, for $m i$ casa es tu casa. So, it will often be up to the translator or the translation brief to establish L3 presence and its nature, and for the scholar or researcher to find evidence of what the translator or brief's decision or criterion was. A text may have more than one L1 (possibly a more prototypical case of a truly multilingual text), just as there may be more than one L3 (e.g. Hindi and Punjabi in Monsoon Wedding). In this respect, intratextual translation as referred to above involves translation between $\mathrm{L} 1$ and $\mathrm{L}^{\mathrm{ST}}$ or between two or more different $\mathrm{L}^{\mathrm{ST}}{ }^{\mathrm{s}} \mathrm{s}$. $\mathrm{L}^{\mathrm{ST}}$ may be either natural or invented (Table 1). But a natural language, such as Italian, Catalan, German, or Korean, etc. may be deliberately misrepresented in written 
and audiovisual texts, as in the case of Italian as scripted (stereotyped, abused, and practically meaningless) for A Fish Called Wanda. In addition, Brumme (2008) points out that the language we hear in feature films (and read in literature) is not a completely faithful rendering of language as actually heard on the street, so to speak. So film and literary language can be close, but never completely identical to naturally occurring speech. Invented L $3^{\mathrm{ST}}$ languages may be strongly based on L1, especially when the utterances are relevant or somehow informative, to make them more easily comprehensible. However, it is also possible for the invented language to have some other natural language (i.e. $\neq \mathrm{L} 1$ ) as its basis. Natural L3 ${ }^{\text {ST }}$ may even happen to be the same language as L2 (e.g. French Kiss translated into French, or Land and Freedom into Spanish). So the following representation is also possible: $\mathrm{L}^{\mathrm{ST}}=\mathrm{L} 2$, or $\mathrm{L} 3^{\mathrm{ST}} \neq \mathrm{L} 2$. What we have said so far in this section for ST and $\mathrm{L}^{\mathrm{ST}}$ can also be said for a translated text and its $\mathrm{L}^{\mathrm{TT}}\left[\mathrm{TT}\right.$ languages $=\mathrm{L} 2+\mathrm{L}^{\mathrm{TT}}$ ] by simply changing L1 for L2, and vice versa, in all instances of this section, and ST for TT.

We propose the label "natural real" when the third language is or represents a natural language (standard, official, or variety, dialect), of the past (e.g. Latin) or present (modern languages), that is to say, the "human vocal noise (or the graphic representation of this noise in writing) used systematically and conventionally by a community for purposes of communication" (Crystal 1985:251). It is shared by all the people who belong to a community of speakers. In our proposal, a language $\mathrm{L}$ (L1, L2, and L3) might be a standard language, or a dialect, or some other form of language variation (for example, an antilanguage, as proposed by Halliday 1975). In this respect, it should be noted that we may refer to a third language regardless of whether the language used in the source text, the L $3^{\mathrm{ST}}$, is some kind of neutral or standard, or, otherwise stresses the features of intralingual variation (e.g. noticeable, relevant dialectal traits); for example, the South American variety of Spanish $\left(\mathrm{L} 3^{\mathrm{ST}}\right)$ spoken by the bandits in Butch Cassidy and the Sundance Kid (George Roy Hill 1969), where the main language of the film (L1) is English; or the Iberian Spanish (L3 ${ }^{\mathrm{ST}}$ ) spoken in Land and Freedom (Ken Loach 2004), which also has English as L1. The concept of L3 stresses the fact that not all the voices in a text (e.g. a film or a novel) speak the same language or the same variety. Thus, we are more interested in signalling the factors involved in translating Nadsat (A Clockwork Orange, Stanley Kubrick 1971), for example, as L3 ${ }^{\text {ST }}$, than worrying about whether or not it constitutes a separate language from English. The point is not to show the difference between what is considered language, dialect or language variation and accent, but rather to broaden the potential applicability of our proposal for L3, which need not be restricted to narrow definitions of language distinctions that coincide with international borders, or officially recognised speech communities. 
From the perspective of translation we regard L1 and L2, not so much as languages in an abstract or general sense (English, Spanish, Italian, Chinese), but rather as a label for a specific audience, or readership (no matter how broad), who is assumed to have a certain linguistic profile. This profile includes the assumption that they may be bilingual, monolingual, or even ignorant of certain dialects or jargons of their "own" language, which would be somewhat "foreign" to them (e.g. the Harlem dialect utterances subtitled, as a joke, in a court scene of Airplane, (Jim Abrahams 1980). So, when we use expressions such as "language of the source text" or "target text language", we should probably be more accurate if we used them to mean "the language of the intended source/ target text users".

Nonfictitious L3 ${ }^{\text {ST }}$ may be close or familiar to the L1 culture and its members; or it may be unfamiliar, somehow exotic. This may be a matter of degree, rather than a close-versus-far dichotomy. As we have said, a translator might wish to distinguish between a natural L3 (that is quite close to "real", or realistic, regarding its words, phrases and pronunciation), and, for example, some kind of pseudo-language that no actual native speaker of the language would recognise as anything but a parody or fake version of the language. A pseudo-language is only meant to pass as real language among viewers who are very unfamiliar with it, or as a parody of the language; or an "impostor" may claim proficiency in the language and pretend to be using it without really having proficiency (which is the case of our example from A Fish Called Wanda). The important feature of such pseudo-languages may often be that they are meant to be recognisable as Italian, or Russian, or whatever, by an audience who may think they can recognise these languages in one or two key words or features (e.g. pronunciation, or even paralinguistic or non-verbal features such as accompanying gestures or types of voice).

An L3 is invented when the language does not have any, and has never had any, actual native speakers. L3 as an invented language may be:

a. An unprecedented mixture of words from different natural languages. An example of this is Cityspeak ( $3^{\mathrm{ST}}$ ) in Blade Runner, which, being a mixture of various languages could reasonably be left untouched from ST to TT, depending on the importance of intended comprehensibility and recognisability of the language. If it is broadly comprehensible to the L1 target audience, then we might say that it is L1-based (Nadsat from A Clockwork Orange, and accordingly translated from L1-based English to L2-based Spanish).

b. A combination of made-up terms, which are not elements of any natural language, although that is how they may be intended to be interpreted. Typical examples could be drawn from languages supposedly spoken by extraterrestrials or characters from other worlds within this one. So, another important 
and interesting distinction is whether such instances of L3 are meant to be comprehensible or not (and how they are made comprehensible).

\section{L3 and types of solutions in translation}

Having presented the two types of third language, it is worth noting how L3 might occur in audiovisual (AV) texts in the case of dubbing. The third language in the audiovisual source text (AV ST) can be spoken and/or written. Thus, AV L3 ${ }^{\text {ST }}$ can be: (i) a language spoken by one or more characters, or otherwise heard in songs or voiceover, etc.; and/or (ii) words in writing (captions, credits, inserts, and visual props like email, newspaper headlines, road signs).

In the light of these distinctions, various translation possibilities might emerge. L3 can be transferred to the TT as an invented language or a natural language (Table 1, applied to the case of $\mathrm{L} 3^{\mathrm{TT}}$ in the translation). $\mathrm{L} 3^{\mathrm{TT}}$ might be the same invented language as the one used in the ST. In other words, L3 is transcribed, so to speak, or, following Delabastita's (1993:39) terminology, repeated. This is probably more likely if $\mathrm{L} 3^{\mathrm{ST}}$ is not strongly based on L1. L3 ${ }^{\mathrm{TT}}$ could be a different language from L3 ${ }^{\mathrm{ST}}$ (a given L3 is substituted for a different one in the translation). If $\mathrm{L}^{\mathrm{TT}}$ is a natural language, then it might happen to coincide with one of the following languages:

i. $\quad$ L3 $3^{\mathrm{TT}}=\mathrm{L} 2$, if $\mathrm{L} 3$ happens to coincide with the main language of the translation it will probably become difficult or impossible to appreciate any multilingualism, if these two languages are not really two but one, in which case the linguistic elements that signal Otherness in the ST run the risk of being read (or heard, for the target audience) as 'familiar' signs of Sameness (Grutman, 2006). This would give rise to L3 invisibility, or, alternatively, L3-ness would have to be conveyed through some L2 strategy (e.g. talked about, or some 'Allo 'Allo-like strategy).

ii. $\quad \mathrm{L}^{\mathrm{TT}}=\mathrm{L} 3^{\mathrm{ST}}$, the language remains unchanged, it is repeated. If $\mathrm{L} 3^{\mathrm{TT}} \neq \mathrm{L} 2$, then L3 status is kept in the translation, although its function(s) or connotation(s) may change, especially if L1 and L2 cultures have very different long-standing relationships with L3 and its culture or countries. It may be a useful and important reminder here to point out that throughout we are only interested in which languages are involved, not the words or their location in the text. So, even in this case of L3 being the same language both for the source text and its translation, the translator may decide to change some or all of the actual words involved depending on other considerations (e.g. comprehensibility, 
familiarity with certain foreign expressions, differences in L3 stereotypical expressions for L1 and L2 speakers).

iii. $\mathrm{L}^{\mathrm{TT}}=\mathrm{L} 1$. This means that $\mathrm{L} 3^{\mathrm{ST}}$ is substituted for $\mathrm{L} 1$ in the translation. A translator may decide for some reason that $\mathrm{L} 3^{\mathrm{ST}}$ is not the best candidate to be used as $\mathrm{L} 3^{\mathrm{TT}}$ (e.g. because $\mathrm{L} 3^{\mathrm{ST}}=\mathrm{L} 2$ ), and may therefore choose the main language of the source text to be used in the translation to add L3 flavour to it. For example, it may be that if the focus is on stereotyping, the L1 language or its speakers fit the same stereotype for L2 speakers as L ${ }^{\text {ST }}$ for L1 speakers.

iv. $\mathrm{L}^{\mathrm{TT}} \neq \mathrm{L} 1, \mathrm{~L} 3^{\mathrm{ST}}, \mathrm{L} 2$. In other words, $\mathrm{L} 3$ does not coincide with any language used in the source text, or with the main language of the target text. This might be the case of a translator who decides to adapt or establish that the relationship between L3 ${ }^{\text {TT }}$ and L2 is meaningfully equivalent to the relationship between L3 ${ }^{\text {ST }}$ and L1 (again, probably to do with stereotypes or long-standing historical grievances or alliances).

v. $\quad \mathrm{L}^{\mathrm{TT}}=\varnothing$. L3 may not appear in (some parts of) the translation if the $\mathrm{L} 3^{\mathrm{ST}}$ segments are deleted in the target text. This may result in greater standardisation of the target text. The operations mentioned in these five possibilities are laid out in Table 3.

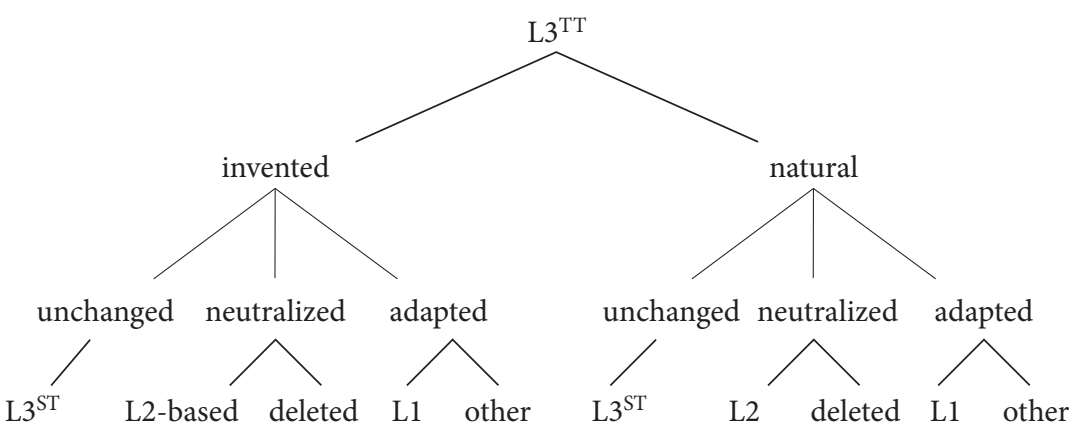

Diagram 1. $\mathrm{L}^{\mathrm{TT}}$ types for translation as $\mathrm{L} 1+\mathrm{L} 3^{\mathrm{ST}} \rightarrow \mathrm{L} 2+\mathrm{L} 3^{\mathrm{TT}}$

Diagram 1, inspired by Zabalbeascoa's (2004) binary-branching proposal for problems, solutions and solution-types, illustrates different types of third languages that might be encountered in a TT according to whether they are the result of $\mathrm{L}^{\mathrm{ST}}$ being neutralised, adapted, or left unchanged both for invented and natural languages. Neutralised L3 is the result of using the L2 (e.g. instead of L1) as an important basis for L3, or as its substitute, or by deleting segments that might call for L3 $\left(\mathrm{L} 3^{\mathrm{TT}}=\varnothing\right)$. Adapted means that L3 has been substituted for a language that is different to $\mathrm{L} 2$. In the neutralised case of $\mathrm{L} 3^{\mathrm{TT}}=\mathrm{L} 2$, the text user for the translation can hardly perceive the presence of anything like L3 (thus producing L3 invisibility). In some cases, this is somehow compensated for by some "oddity" or 
idiolect, as in the US TV series Fresh Prince of Bel Air (Charles Braverman 1986), where a British butler with a posh English accent (RP English as L3 ${ }^{\mathrm{ST}}$ ) works in Bel Air for an American family (US English as L1). The Spanish dubbed version provides the butler with apparently the same language (L2) as all the other characters, but exaggerating the poshness to the point where the butler comes across as a caricature of effeminacy (possible new L3 as an instance of a special form of the main language, L2). British English is a recurrent L3 in Hollywood and Disney productions, often to signal characters who are in some way evil or odd, just as L3 often is for Hollywood when L3 is German, Russian, Italian, Spanish, and so on. In Spanish dubbed versions, such fertile ground for breeding Xenophobia (see Zabalbeascoa 2000a for a study of the Spanish dubbed version of Aladdin) is often made barren, at least on a linguistic level, by resorting to $\mathrm{L}^{\mathrm{ST}} \rightarrow \mathrm{L} 2$, thereby reducing L3 status to nil. In the case of subtitling, foreign accents are rarely signalled. This is but one example of the close relationship between language variety (including multilingualism) and sociolinguistic, ideological, cultural and political implications, and how they might affect and be affected by translation. Our scope in this paper, however, is restricted to mapping options for dealing with multilingualism as a translation problem in terms of L1, L2 and L3 differences and coincidences, as a previous stage. We cannot provide a fully informed analysis of ideological and other motivations and effects without first charting the territory to be explored.

Having provided potential scenarios and occurrences of L3, our aim is to describe and document certain instances of how L3 is rendered in translation, and, in proposing a model of potential coincidences and differences, we hope to provide insight and suggestions for future translation practice.

Translating an audiovisual text with one or more L3s, for instance, is not necessarily more constrained than other forms of translation insofar as the third language is simply a textual feature that translators have to deal with (like metaphors, proper nouns, symbolism and many others). L3 notation is to be used to refer to the presence in a text of languages that only account for a small part of the total linguistic output of a text. When two or more languages are so evenly distributed that it becomes difficult to establish a principal language, or even when a secondary language covers considerably long passages, then it might be more appropriate to consider that in fact we are dealing with a text, or a translation, that has more than one L1 (L1a, L1b, L1c, ...) or maybe even L2, respectively. Likewise, there may be more than one L3 in a given ST or TT (L3a, L3b, L3c, ...).

The notion of equivalence between a ST and any of its TT can be explained in terms of (contingent) similarities and differences between the two texts. Translators are faced with a source text made up of a complex combination of features and items (elements), semiotic, rhetorical, syntactic, pragmatic, etc. and they are supposed to mirror all this in their translation, but they are rarely able to transfer 
all the elements to the same degree. So, for each case, how is the TT going to be similar to its ST? When translators are working to translate a text, they come across obstacles that prevent 'perfect' translation. These difficulties are what Zabalbeascoa (1999) calls restrictions and their presence obliges translators to prioritise their aims in order of importance. In doing so, translators are establishing criteria for equivalence, which will allow the target text to be more similar in some aspects than others. Similarly, Eco (2003:30) states that "translators are in theory bound to identify each of the relevant textual levels, but they may be obliged to choose which ones to preserve, since it is impossible to save all." In this respect, it should be noted that there is no single way of translating an L3 because there are many variables that can influence translators' decisions. Several solutions are plausible depending on the aims of the translation and the translators' priorities and restrictions (textual, stylistic, ideological, linguistic, cultural, among others).

When L3 is identified as a problem, translators need to decide how to render it in the TT, i.e. how to solve the problem. There are various possible solutions to choose from, which range from not marking it $\left(\mathrm{L} 3^{\mathrm{TT}}=\mathrm{L} 2\right.$; or $\mathrm{L} 3^{\mathrm{TT}}=\varnothing$, i.e. delete $\left.\mathrm{L} 3\right)$, to clearly distinguishing between different speech groups by what they say or the way they speak. In this paper, L3 possibilities are proposed without judging motivations, efficacy, or conformity to norms. Thus, following Corrius (2008:383), L3 ${ }^{\text {TT }}$ can be classified according to the degree or nature of manipulation: (i) unchanged (L3 ${ }^{\mathrm{TT}}$ is the same as $\mathrm{L} 3^{\mathrm{ST}}$ ), (ii) neutralized ( $\mathrm{L}^{\mathrm{ST}}$ is the same as $\mathrm{L} 2$, so they cannot be differentiated in the TT), and (iii) adapted (the $\mathrm{L}^{\mathrm{TT}}$ is not $\mathrm{L} 3^{\mathrm{ST}}$ nor has it been neutralised or omitted). Unchanged and adapted L3s can be invented or natural (Diagram 1).

Diagram 1 illustrates the set of possible types of L3 found in the TT resulting from the translation of a given feature of the ST (its third language), which is perceived as a problem (i.e. something to be solved or rendered somehow in the TT). If we were to follow Toury's (1995: 14-19) study of metaphor translation we would also have to foresee the possibility of instances of $\mathrm{L} 3^{\mathrm{TT}}$ that could not be accounted for by the presence of $\mathrm{L} 3^{\mathrm{ST}}$, i.e. a translator might choose to introduce an instance of $\mathrm{L} 3^{\mathrm{TT}}$ as a solution to a different kind of problem, in the absence of any L3 ${ }^{\mathrm{ST}}$. This might be achieved by leaving (repeating) L1 segments unchanged, that is, instead of rendering them into $\mathrm{L} 2$, rendering them as $\mathrm{L} 3^{\mathrm{TT}}=\mathrm{L} 1$. Or it might be a part of permutation or compensation, i.e. L3 is added to a part of the translation to make up for it being deleted or lost elsewhere.

\section{TT solutions for rendering $\mathrm{L} 3^{\mathrm{ST}}$ in translation}

From what we have seen thus far it follows that translators have a range of possible

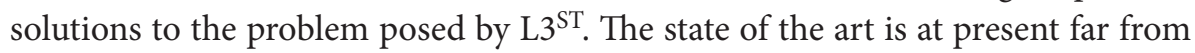


achieving a complete mechanism to show exactly how L3 is or might be translated. According to Meylaerts (2006) translating heterolingual texts has become a research issue in Translation Studies, but it has not yet received the attention it deserves. She considers that translation is still viewed as the full transposition of one (monolingual) source code into another (monolingual) target code. Our approach based on the factors (priorities and restrictions) involved in the process of translating, and binary branching for discovering solution-types is intended as a contribution to the area of translating multilingual and heterolingual texts.

Considering L3 as a potential textual restriction for translation, we outline criteria for mapping possible solutions for the translation of a given third language. First of all, translators are assumed to identify L3 and decide whether it is a problem that requires a solution involving $\mathrm{L}^{\mathrm{TT}}$ or not. If this is not deemed appropriate, they might render $\mathrm{L} 3^{\mathrm{ST}}$ as L2 in their translation, or omit it altogether, which would also yield L2 for the surrounding parts of the translation if not all of it. If the solution involves highlighting the third language in the TT - i.e. if L3 is to remain distinguishable in the TT - other options will have to be explored. In this case, translators will need to analyse the nature and function of $\mathrm{L}^{\mathrm{ST}}$ in the ST (the nature of the problem and the priorities involved). Here, it is worth mentioning that various solutions might be provided according to whether there is intended equivalence (when ST item or feature $\mathrm{X}$ is a priority for the TT because it was a priority for the ST), intended difference (when X is a priority for the TT, but it was not for the ST) or indifference to equivalence (when $\mathrm{X}$ is a priority for the TT, no matter if it was a priority for the ST or not) (Zabalbeascoa 1999). ST item or feature $\mathrm{X}$ may be the $\mathrm{L}^{\mathrm{ST}}$ itself or something related to its presence (e.g. humour). If $\mathrm{L} 3$ is meant as a component of humour, then presumably the problem to be solved will be how to produce humour, which will provide a sense of purpose in how to deal with L3. L3 is frequently a means rather than a goal in itself. The set of possible TT solutions for the translation of $\mathrm{L}^{\mathrm{ST}}$ and their various effects in the TT is summarised in Table 2 and Table 3.

The proposal illustrated in Tables 2 and 3 is intended to cover the set of possible solutions for the problem "third language" present in a source text and their effects in the corresponding translation. L1 is the main language of the ST, and L2 the main language of the TT. Likewise, $\mathrm{L}^{\mathrm{TT}}$ stands for the third language of the TT whereas $\mathrm{L}^{\mathrm{ST}}$ stands for the third language of the ST, but because texts can include various languages as well as dialects and sociolects, $\mathrm{L} 3^{\mathrm{ST}}$ and $\mathrm{L} 3^{\mathrm{TT}}$ may cover - if relevant - other varieties which are different from the official or standard. It is also worth mentioning that Tables 2 and 3 cover the relationships we have identified between the ST and the TT, including Jakobson's (1959) interlingual translation (Table 22). The Tables illustrate the operations that can be performed on instances of L1 and L3 ${ }^{\mathrm{ST}}$, respectively, in the column headed 'operation. For 
this, we have found it interesting to use Delabastita's (1993:39) terminology, to show how our proposal can link up with other theoretical studies. The two columns in the middle show the nature and degree of L3 presence and visibility in the translation, whether it is lost, kept, added, or simply not applicable. The column headed 'possible effect / result' on the right shows possible (but by no means all) effects and results of carrying out each operation as it affects the target text and its $\mathrm{L}^{\mathrm{TT}}$, regardless of whether other problems may or may not have been solved (e.g. humour, character portrayal). Further, the current version of our model is restricted by its feature of adapting Delabastita's categories, so it cannot reflect, as already stated, ideological and sociocultural dynamics and motivations, which, we are sure, are often present and constitute a powerful explanatory tool for L3 presence and variation.

In any standard interlingual translation practice there is an exchange of L1 for L2 in the TT (Table 22). However, on occasion, for some textual segments, the transfer is unchanged - an L1 segment is not replaced by L2 elements in the TT, but it is kept as L1. In this case, L1 becomes L3 in the TT (Table 23), in which case $\mathrm{L} 1$ changes its status to $\mathrm{L} 3^{\mathrm{TT}}$. In other words, $\mathrm{L} 3$ is created in the process of translation. Otherwise, L1 can be exchanged for any language other than L2 (Table 24), for example if translations are aimed at introducing some sort of discourse variation, in which case the third language created in the TT is different from L1. L3 might be created for the purpose of adaptation or some sort of equivalence in the text, or even to compensate for other segments where $\mathrm{L} 3^{\mathrm{ST}}$ was not rendered as $\mathrm{L}^{\mathrm{TT}}$. For example, given the different relation between Italian and English, and Italian and Spanish, and if we wished to fulfil the requirement of comprehensibility, the smatterings of Italian as L3 in an English version (ST) translated into Spanish (TT), may appear in different parts of each version (i.e. wherever they are more

Table 2. Operations for L1 segments

\begin{tabular}{|c|c|c|c|c|}
\hline & Operation & $L 3^{T T}$ segment & $L 3^{T T}$ status & Possible result/ effect \\
\hline (1) & delete L1 & $\varnothing$ & $\mathrm{NO}$ & $\begin{array}{l}\text { Neutralization of } \\
\text { peculiarities }\end{array}$ \\
\hline 2 & substitute L1 $\Rightarrow$ L2 & $\varnothing$ & $\mathrm{NO}$ & $\begin{array}{l}\text { Traditional, standard } \\
\text { interlingual translation }\end{array}$ \\
\hline 3 & repeat L1 $\Rightarrow \mathrm{L} 1$ & $\mathrm{~L} 3^{\mathrm{TT}}=\mathrm{L} 1$ & added & $\begin{array}{l}\text { L3 created by not } \\
\text { translating, exoticization }\end{array}$ \\
\hline 4 & $\begin{array}{l}\text { permutate or substitute } \\
\left(\mathrm{L} 1 \Rightarrow \mathrm{L} 3^{\mathrm{TT}}\right)\end{array}$ & $\mathrm{L}^{\mathrm{TT}} \neq\left\{\begin{array}{l}\mathrm{L} 1 \\
\mathrm{~L} 2\end{array}\right.$ & added & $\begin{array}{l}\text { Exoticization used as a } \\
\text { compensation strategy }\end{array}$ \\
\hline
\end{tabular}


comprehensible, for each case); in terms of traditional translational procedures (e.g. Vinay and Darbelnet 1957), it would be a case of rendering Italian L3 ${ }^{\mathrm{ST}}$ as L2 in the TT, and compensating for this "loss" (of L3 presence) by rendering other elements of $\mathrm{L} 1$ as $\mathrm{L} 3^{\mathrm{TT}}$.

The third language present in a ST can be omitted in the TT, meaning that for all practical purposes $\mathrm{L} 3$ ceases to exist as such and becomes invisible in the text. Thus, there is an overall linguistic standardisation (Table 30).

If the third language of the ST is different from the main language of the TT $\left(\mathrm{L}^{\mathrm{ST}} \neq \mathrm{L} 2\right), \mathrm{L}^{\mathrm{ST}}$ can be transferred unchanged and still retain $\mathrm{L} 3$ status as an $\mathrm{L}{ }^{\mathrm{TT}}$ $\left(\mathrm{L}^{\mathrm{TT}}=\mathrm{L} 3^{\mathrm{ST}}\right.$ ), e.g. the Japanese in Lost in Translation (Sofia Coppola 2003), which is also kept in the Spanish TT. In this case, L3 is retained but its effect and function may change, depending on differences in L1/L3 and L2/L3 relationships (Table $3 \boldsymbol{6}$ ). But, when the third language of the ST coincides with the main language of the TT $\left(\mathrm{L}^{\mathrm{ST}}=\mathrm{L} 2\right)$, it may cross over unchanged (and unnoticed) in the TT, which means it can no longer be differentiated from the TT main language (8); this happens in the case of, for instance, the Spanish commander's instructions in Land and Freedom. L3 status is then lost. If the third language of the ST is different from the main language of the $\mathrm{TT}\left(\mathrm{L} 3^{\mathrm{TT}} \neq \mathrm{L} 2\right.$, as in $\boldsymbol{\nabla}$ ) but $\mathrm{L} 3$ is not retained in the TT, $\mathrm{L}^{\mathrm{TT}}$ status is also lost and becomes invisible, for example the Punjabi spoken by non-educated people in Monsoon Wedding (Mira Nair 2001), which is not noticeable in the Spanish TT. In this case, translators may also resort to some form of compensation, for example, making certain characters talk in L2 about foreignness.

On occasion, the TT third language may not be the same as the ST third language insofar as not all texts are translated in the same way; it depends on where and in what historical moment the translation is carried out. Different audiences may demand different responses (Cronin 2009:25). Hence, L1 or any other language might be used as the third language of the TT. If $\mathrm{L} 3^{\mathrm{TT}}$ happens to be $\mathrm{L} 1$, then the linguistic relationship is maintained, but reversed, and familiarity may change depending on differences in familiarity of the $\mathrm{L} 3$ for the respective audiences. The choice of L3 may also be adapted to the TT and L2 environment $(\boldsymbol{\Theta})$, precisely based on criteria like familiarity, or bias and other such connotations, (e.g. the French in the Spanish version of Butch Cassidy and the Sundance Kid, where the $\mathrm{L}^{\mathrm{ST}}$ is Spanish and the $3^{\mathrm{TT}}$ is French).

In light of the above, we can take for granted that multiple operations are plausible in the translation of a text with more than one instance of L3, especially if there is more than one distinct L3. As far as the number of different L3s embedded in a text is concerned, we might say that the greater the number of third languages involved, the more complex the analysis would be. Table 3 provides different solutions for the translation of a single third language in the source text, but multilingual source texts that contain more than one third language involve applying the 
Table 3. Operations for $\mathrm{L}^{\mathrm{ST}}$ segments

\begin{tabular}{|c|c|c|c|c|}
\hline & Operation & $L 3^{T T}$ segment & $\begin{array}{l}L 3^{T T} \\
\text { status }\end{array}$ & Possible result/ effect \\
\hline 5 & delete $\mathrm{L} 3^{\mathrm{ST}}$ & $\varnothing$ & lost & Standardization \\
\hline $\boldsymbol{6}$ & $\begin{array}{l}\text { repeat } \mathrm{L} 3^{\mathrm{ST}} \Rightarrow \mathrm{L} 3^{\mathrm{TT}} \\
\quad\left(\text { when } \mathrm{L} 3^{\mathrm{ST}} \neq \mathrm{L} 2\right)\end{array}$ & $\mathrm{L} 3^{\mathrm{TT}}=\mathrm{L} 3^{\mathrm{ST}}$ & kept & $\begin{array}{l}\text { Function or connotation } \\
\text { may change }\end{array}$ \\
\hline ? & $\begin{array}{r}\text { substitute L3 }{ }^{\mathrm{ST}} \Rightarrow \mathrm{L} 2, \\
\left.\text { (when } \mathrm{L}^{\mathrm{ST}} \neq \mathrm{L} 2\right)\end{array}$ & \multirow{2}{*}{$\begin{array}{c}\varnothing \\
\left(\mathrm{L} 3^{\mathrm{TT}}=\mathrm{L} 2\right)\end{array}$} & \multirow{2}{*}{ lost } & \multirow{2}{*}{$\begin{array}{l}\text { L3 invisibility, or L3 } \\
\text { quality conveyed through } \\
\text { some L2 strategy (e.g. } \\
\text { talked about). } \\
\text { Standardization, with or } \\
\text { without compensation. }\end{array}$} \\
\hline 8 & $\begin{array}{l}\text { repeat } \mathrm{L} 3^{\mathrm{ST}} \\
\qquad\left(\text { when } \mathrm{L} 3^{\mathrm{ST}}=\mathrm{L} 2\right)\end{array}$ & & & \\
\hline 9 & $\begin{array}{l}\text { substitute } \mathrm{L} 3{ }^{\mathrm{ST}} \\
\begin{array}{l}\text { (when } \mathrm{L} 3^{\mathrm{ST}} \neq \mathrm{L} 2 \\
\text { or } \mathrm{L} 3^{\mathrm{ST}}=\mathrm{L} 2 \text { ) }\end{array}\end{array}$ & $\begin{array}{l}\mathrm{L}^{\mathrm{TT}} \neq\left\{\begin{array}{l}\mathrm{L}^{\mathrm{ST}} \\
\mathrm{L} 2\end{array}\right\} \\
\mathrm{L} 3^{\mathrm{TT}}\left\{\begin{array}{l}\neq \\
=\end{array}\right\} \mathrm{L} 1\end{array}$ & kept & $\begin{array}{l}\text { Function or connotation } \\
\text { may be equivalent or } \\
\text { analogous }\end{array}$ \\
\hline
\end{tabular}

insight of this sort of diagram separately for each of the third languages present in the ST insofar as the inclusion of more than one language in a single text (audiovisual or otherwise) does not necessarily entail translating each language in the same way, and by the same means (solution-types).

\section{Conclusions}

Apart from the difficulties posed by any translation task, translators may be faced with another problem which can become a recurrent textual restriction: that of the third language (L3). We have found multiple instances of this phenomenon in audiovisual texts, and it is also often present in other modes of communication. Our approach regards translating as a set of operations whereby the source text involves $\mathrm{L} 1+\mathrm{L}^{\mathrm{ST}}$ and the target text $\mathrm{L} 2+\mathrm{L}^{\mathrm{TT}}$, in a range of different combinations. L3 is a minority language - or languages - for a text, and this means that two or more languages may hold L1 or L2 status if they are of more or less equal importance.

Translating a ST that contains a third language is not necessarily more constrained than other forms of translation; L3 is simply a textual feature translators need to deal with. When L3 is embedded in a ST, translators may adopt different 
attitudes towards the problem; they might omit L3 or reflect it in the target text. In the latter case, the third language might be rendered in a number of ways and its transfer does not necessarily entail that the third language will be preserved to the same degree as it was in the source text, or fulfil the same textual functions. The criteria proposed for mapping possible solutions for the translation of a given third language are the following:

1. We may assume that translators may or may not identify a third language and then decide whether it is necessary to highlight it in the target text, or not (i.e. make it invisible). Thus, they will need to analyse the nature of this language (including its form and familiarity) in the ST and hypothesize about its function in the text. It is worth mentioning that the presence of a third language in an audiovisual text is meant to be considered in relation with all the other elements in the text, regardless of whether they belong to different or the same channels (audio and visual) and/or codes (verbal and otherwise).

2. Translators decide on how they may transfer the third language to the target text and establish criteria for equivalence or effect (either for the L3 as such or other features, such as humour, it might carry with it). They (or their commissions) decide the degree to which the third language is to be identifiable in the translation, which ranges from not marking it (L3 invisibility) to clearly distinguishing between the in-group and the out-group by means of language variation. Translators decide on the best solution for each given feature of the source text, including L3 and its relationship to other ST and TT features. Solutions as presented in Diagram 1 and the operations in Tables 2 and 3 are classified according to no other criterion than how they relate to L1, L2, and L3 ${ }^{\text {ST }}$. They are not meant to provide an account of the translator's priorities and motivations, which is of course essential, and could benefit from an initial-stage mapping such as the one presented here. In this respect (Diagram 1) the TT third language can be classified as unchanged (the $\mathrm{L}^{\mathrm{ST}}$ is retained in the $\mathrm{L} 3^{\mathrm{TT}}$ ), neutralized (the $\mathrm{L} 3^{\mathrm{ST}}$ coincides with the $\mathrm{L} 2$, so the two cannot be distinguished in the TT), and adapted (the $\mathrm{L} 3^{\mathrm{ST}}$ is rendered in a different language, which does not coincide with any of the languages involved in both the ST and the TT). Adapted languages can be invented or natural.

3. Finally, for the particular case of dubbing, translators may be seen as creating a 'new' script for their 'new' audience (or readership). The set of possible targettext solutions for rendering the third language in a multilingual source text are shown in Tables 2 and 3, which cover all the possible options for each third language problem that we have found. The Tables also show that the third language in ST may or may not coincide with the language of the TT $\left(\mathrm{L} 3^{\mathrm{ST}}=\mathrm{L} 2\right.$ or $\mathrm{L}^{\mathrm{ST}} \neq \mathrm{L} 2$, respectively). From our study it may be inferred that there may 
be little difference between translating a third language that coincides with the L2 language $\left(\mathrm{L} 3^{\mathrm{ST}}=\mathrm{L} 2\right)$, and a third language that is different from the targettext audience's. Tables 2 and 3 are expected to be useful awareness-raisers for such situations. The various solutions are plausible depending on translators' priorities and restrictions (including ideological factors, motivations, and social norms). ${ }^{2}$

\section{Notes}

1. Patrick Zabalbeascoa contributed as part of the research project The Translation of Fictional Dialogue (TRADIF is its acronym), ref. FFI2010-16783 (FILO-2010-2013), financed by the Spanish Ministry of Science and Innovation.

2. We would like to thank the editors of Target for their help with improving the text of this article.

3. We use the term 'translator' to refer to any person or group of people doing - or otherwise involved in producing - a TT, regardless of their variable personal and professional characteristics, or their degree of coordinated teamwork and assistance (technological or otherwise).

\section{References}

Antonini, Rachele. 2008. “The perception of dubbese: An Italian study”. Delia Chiaro, Christine Heiss and Chiara Bucaria, eds. Between Text and Image: Updating research in screen translation. Amsterdam and Philadelphia: John Benjamins, 2008. 135-147.

Baker, Mona. 1993. "Corpus Linguistics and Translation Studies: Implications and Applications". Mona Baker, Gill Francis, Elena Tognini-Bonelli, eds. Text and Technology: in Honour of John Sinclair, Amsterdam and Philadelphia: John Benjamins, 1993. 233-250.

Bassnett, Susan. 1992. Translation Studies (Revised Edition). London: Routledge.

Bleichenbacher, Lukas. 2008. Multilingualism in the Movies. Hollywood Characters and their Language Choices. Tübingen: Francke.

Brumme, Jenny 2008. La oralidad fingida: descripción y traducción. Teatro, cómic y medios audiovisuales. Madrid: Iberoamericana; Frankfurt and Main: Verveurt.

Corrius, Montse. 2008. Translating Multilingual Audiovisual Texts. Priorities and Restrictions. Implications and Applications. Unpublished Ph.D. thesis, Barcelona: Universitat Autònoma de Barcelona.

Cronin, Michael. 2009. Translation Goes to the Movies. London and New York: Routledge

Crystal, David. 1985. Linguistics. Harmondsworth: Penguin Books.

Delabastita, Dirk. 1993. There's a Double Tongue. An Investigation into the Translation of Shakespeare's Wordplay. Amsterdam and Atlanta: Rodopi.

Delabastita, Dirk. 2002. "A Great Feast of Languages". The Translator 8:2. 303-340. 
Delabastita, Dirk. 2010. "Language, Comedy and Translation in the BBC Sitcom 'Allo 'Allo!" Delia Chiaro, ed. Translation, Humour and the Media. Translation and Humour Volume 2. London: Continuum, 2010. 193-221.

Eco, Umberto. 2003. Mouse or Rat? Translation as Negotiation. London: Orion Books Ltd.

Frawley, William. 1984. Translation. Literary, Linguistic \& Philosophical Perspectives, Newark: University of Delaware Press.

Grutman, Rainier. 1998. "Multilingualism and translation", in Mona Baker (ed.), Routledge Encyclopedia of Translation Studies. London and New York: Routledge,1998. 157-160.

Grutman, Rainier. 2006. "Refraction and recognition. Literary multilingualism in translation". Target 18:1. 17-47.

Halliday, M. A. K. 1975. "Anti-Languages”. American Anthropologist 78 (3). 570-584.

Heiss, Christine. 2004. “Dubbing Multilingual Films: A New Challenge?”. Meta 49:1. 208-220.

Jakobson, Roman. 1959. “On Linguistic Aspects of Translation”. R. A. Brower, ed. On Translation. Cambridge, MA: Harvard University Press, 1969. 232-39.

Meylaerts, Reine. 2006. "Heterolingualism in/and translation. How legitimate are the Other and his/her language? An introduction”. Target 18:1. 1-15.

Newmark, Peter. 1988. A Textbook of Translation. Hemel Hempstead: Prentice Hall.

Toury, Gideon. 1995. Descriptive Translation Studies and beyond. Amsterdam and Philadelphia: John Benjamins.

Vinay, J. and Darbelnet, J. 1957. Stylistique comparée du français et de l'anglais, Paris: Didier.

Zabalbeascoa, Patrick. 1999. "Priorities and Restrictions in Translation”. Jeroen Vandaele, ed. Translation and the (Re)Location of Meaning. Leuven: CETRA, 1999. 159-167.

Zabalbeascoa, Patrick. 2000a. "Contenidos para adultos en el género infantil: el caso del doblaje de Walt Disney". Veljka Ruzicka et. al. eds. Literatura infantil y juvenil: tendencias actuales en investigación. Vigo. Universidade de Vigo, 2000. 19-30.

Zabalbeascoa, Patrick. 2000b. "From Techniques of Translation to Types of Solutions". Allison Beeby, Doris Esinger, Marisa Presas, eds. Investigating Translation. Amsterdam and Philadelphia. John Benjamins. 2000. 117-127.

Zabalbeascoa, Patrick. 2004. "Translating non-segmental features of textual communication: the case of metaphor within a binary-branch analysis". Gyde Hansen, Kirsten Malmkjær and Daniel Gile, eds. Claims, Changes and Challenges in Translation Studies. Amsterdam and Philadelphia: John Benjamins, 2004. 99-111.

\section{Literary references}

Brontë, Charlotte. 1994. Jane Eyre. London: Penguin popular classics.

Eco, Umberto. 2000. Baudolino. Milano: Edizione Tascabili Bompiani.

\section{Film references}

'Allo 'Allo!, David Croft and Jeremy Lloyd, BBC, 1982-1992.

Airplane, dir. Jim Abrahams, David Zucker, Jerry Zucker, Paramount Pictures. 1980.

Blade Runner, dir. Ridley Scott, Warner Bros Pictures. 1982.

Butch Cassidy and the Sundance Kid, dir. George Roy Hill, Twenty Century Fox. 1969.

A Clockwork Orange, dir. Stanley Kubrick, Warner Bros Pictures. 1971.

A Fish Called Wanda, dir. Charles Crichton, Metro-Goldwyn-Mayer Studios. 1988. 
French Kiss, dir. Lawrence Kasdan, Metro-Goldwyn-Mayer Studios. 1997.

Fresh Prince of Bel Air, dir. Charles Braverman, Leonard Hill Films. 1986.

Land and Freedom, dir. Ken Loach, Messidor Films. 2004.

Lost in Translation, dir. Sofia Coppola, Focus Features. 2003.

Monsoon Wedding, dir. Mira Nair, IFC Productions. 2001.

\section{Authors' addresses}

Montse Corrius Gimbert

Universität de Vic

Dept. Lleniies i Ciencies Socials

Sagrada Familia, 7

08500 VIC

Spain

montse.corrius@uvic.cat
Patrick Zabalbeascoa

Universitat Pompeu Fabra

Dept. Traducció i Ciències del Llenguatge

Roc Boronat 138.

08018 BARCELONA

Spain

patrick.zabalbeascoa@upf.edu 